\title{
Effect of Glass Ceiling on Women's Career Development in Banks Operating in Pokhara Metropolitan City
}

\author{
Bijay Lama*
}

\begin{abstract}
Although the number of working Nepali women is in the increasing trend, there is lack of data indicating exact number of Nepali women involved in managerial jobs. The general purpose of the study is to find out the effect of glass ceiling on women career development in banks operating in Pokhara Metropolitan City. The dependent variable is career progression refers, employee interested in advancing or achieving their career. Hypotheses indicate that there are significant impact of personal, organizational and societal barrier on women career development. The population which has been selected for the study was female employees working at lower, middle and higher levels of selected commercial banks, development banks and finance companies. The female employees have been selected for this survey and sample size of this study was 99. This research study relied upon the survey method for collection of data. The Cronbach's alpha test was conducted for reliability which resulted 0.727 that define data are closest to reality. The study found that among the glass ceiling's factors most influencing factor is societal barrier. Hence, female employee must have to work in order to avoid the societal barriers. Difficulty in maintaining family and job responsibilities; and lack of family support results women employees not to accept higher post. It is suggested to the financial institutions to conduct activities that focus on maintaining balance between work and family life.
\end{abstract}

Keywords: Family barrier, glass ceiling, organizational barrier, personal barrier, women career development.

\section{INTRODUCTION}

Women related issues including gender based issues have become concerned these days. Many events including seminars and workshops are being held in many parts of the world. It has become significance factor of global labour market (Black, Gregerson, Mendenhall, \& Stroh, 1999; Caligiuri \& Tung, 1999). There has been increasing involvement of the women in middle level and top level position of the organization including involvement in politics. However, their position at top level is still in minority according to Meyerson and Fletcher (2000). Only 10\% senior managers involved in Fortune 500 companies. There is lack of women leader in representation all over the world like Australia (Davidson, 2009), China (Tan, 2008), United Kingdom (Davidson, 2009) and United States (Eagly \& Carli, 2007; Fassinger, 2008). There is few presence and representation of women on corporate governance (Adler \& Izraeli, 1994; Bilimoria \& Piderit, 1994). Tharenou (2001) defines that providing trainings can help women to empower and develop confident.

Women are doing better in current scenario of Nepal. Mrs. Bidya Devi Bhandari elected as first female President of Nepal and Mrs. Shiva Maya Tumbahamphe as a deputy speaker of House of Representatives. As per Central Bureau of Statistics 2015 A.D., It was estimated that there was 13.6

*Mr. Lama is Freelance Researcher.Email:bj.lama2015@gmail.com 
million female populations in comparison to male population of 12.8 million. Meanwhile there was 2.3 million male and 2.5 million female populations in Kaski district.

Comparatively there is higher population of female than male in Nepal. But still there are so many challenges that female are not getting opportunity to get access to top level position in the service sectors (Central Bureau of Statistics, 2009). There has been developed of good perspective towards women but there is still not much effort has been made for the career development of women employees. Hofstede's (1998, as cited in Aaltio \& Huang, 2007) mentioned that influenced to employee, differ from culture variation where Nepali culture has different impact on women in compare to Western cultures (Luthans, 2011). The quota system will provide better opportunity for women and reduce discrimination

As on January 2018, there were altogether 151 financial institutions including 28 commercial banks, 33 development banks, 25 finance companies and 65 micro finance in Nepal (NRB, 2018). The research has focused on studying female employees working in banks located in Pokhara Metropolitan City. As it has clearly been seen that there are few female chief executive at the financial institutions, hence it indicates that there is challenges and problem in career progress of women employees in Nepal.

As per Wall Street Journal, glass ceiling is defined as business women are blocked by company's tradition to get access to the top level position. According to Rana (2007), women have been found in low level positions and service related activities. Though the precise information of women involvement in employment is not available, Nepal labor force survey carried out in the year 2008 by the CBS (2009) estimated that the legislators, senior officials, and professional level women altogether is about 48,000 (i.e., 24\%) out of a total 197,000 personnel within these three occupational categories. This number is only nine percent of the total Nepali women working as paid employees. Within paid occupation, the highest percent of women employees is within elementary occupation (i.e., 54\%), followed by women employees as technicians and associate professionals (i.e., 14\%). And, the lowest percent of women employees is within the legislators and senior official levels (i.e., 0.38\%). Although the number of Nepali women working is in the increasing trend, there is lack of data indicating exact number of Nepali women involved in managerial jobs. Compared with previous labor survey, CBS (2009) reported that gender segregation within management functions still remains same as before. Hansatit (2014) explains that there is absence of glass ceiling however it is only based on perception of women. Aidoo and Achira (2016) finds that role of government, organization, society and individual efforts are significance to reduce barrier of women for career progression. The gender discrimination is higher in top position than in lower and middle level positions (Othman \& Othman, 2015). Adhikary (2016) explains that marriage during their career and lack of job exposures are factors that hindrance their career development. The discrepancy between males and females representation at senior and executive levels remains problematic. Since there have not been study conducted yet among female employees of the bank on topic called glass ceiling, thus, the main purpose of the study is to find out the effect of glass ceiling on women career development of employees who are working in development banks, commercial banks and finance companies at Pokhara Metropolitan City.

The study is focus on examining the effect of glass ceiling on Women Career Development. Also the factors like personal, societal and organizational barriers have been used with bank type, academic level and ethnicity as moderate variables. This study will play significance role to the managers of the banks to formulate effective plans and policies and implement activities that reduce glass ceiling in the organization.

It has been found various national and international scholars have conducted study on the various 
topics that focus on the glass ceiling at the work place. However, in Nepal, there are few scholars who have conducted research on the glass ceiling topic. Those who have conducted has focused on barrier in career progression and perspective of gender issues. Thus, study on focusing glass ceiling topic has not been conducted in context of Nepal. The banks institutions are however not been study excessively. So, this study focused on Nepalese banks and analyzed the effect of glass ceiling on career progression of women employees.

\section{CONCEPTUAL FRAMEWORK}

The main idea emphasized by this conceptual framework is, GC influences the WCD. GC may affect as the independent variable. WCD is the dependent variable. Therefore, women career life is depending on several independent variables. Personal barriers (PB), organizational barriers (OB) and societal barriers (SB) considered as independent variables in this framework.

PB (lack of confidence, personal trait sand inability to sell them-selves), OB (organizational policy, management style) and SB (childcare, house work).In addition to the above mention factors there can be several intervening variables and moderating variables, such as bank type, Ethnicity and academic level factors exist in this study. However they are not considered in the research to avoid unnecessary complexities. For an example, if WCD is influenced by these mentioned variables (moderating); in consequence WCD may vary indirectly or directly. Thus researcher could not precisely measure, effect of GC, because of these other influences, therefore researcher assume here, moderating and intervening variables as fixed constraint and not affect for WCD.

Afza and Newaz (2008) have proposed five major factors which influence GC effects in organizations: management perception, work environment, work- life conflict, sexual harassment, organizational policy. As study indicates management perception and work environment are most significant factors for creating GC whereas organizational policy and work life conflict are the second most significant factors. Conversely respondent disagree about sexual harassment as a contributing factor for creating GC effect in the organization. Based on the above findings researcher developed and take into consideration three factors which influenced the WCD, namely personal barrier (PB), societal barriers (SB) and organizational barriers $(\mathrm{OB})$ formulated following alternative hypotheses,

$\mathrm{H}_{1}$ : There is significant impact of personal barrier on WCD.

$\mathrm{H}_{2}$ : There is significance impact of societal barriers on WCD.

$\mathrm{H}_{3}$ : There is significance impact of organizational barriers on WCD.

\section{DATA AND METHODS}

The population for the study is defined in terms of female employees working at lower, middle and higher levels of commercial banks, development banks and finance companies of Nepal. The study is based on primary data and used survey research design. All together 99 women employees were surveyed for the study. Questionnaires have been administered to collect the data at work place of employees providing them briefing and instruction about the topic related to the questionnaire. The main purpose of this instruction was to give the know-how about glass ceiling and to collect reliable and factual data.

The three dimensions of the independent variable glass ceiling: stereotype of women, work/family conflict and unfavorable corporate practices was measured through questionnaire with five point scales, 
which was completed by the respondents themselves. The variables of the study have constituted interval scales. The dependent variable of the research model was measured by an instrument consisting of statements. The career upward mobility of women managers were measured in terms of two dimensions as career focus and attitude towards the organization (Afza \& Newaz, 2008). These dimensions have consisted of aspects as career focus (willingness to take risks, having a proven record of accomplishments, being entrepreneurial and having specialized training), attitude towards the organization (having corporative and non-threatening leadership style, interest in high stake and challenging assignments and membership in professional bodies). The career upward mobility of women employee was measured by their responses to the questionnaire with five point Likert scales of strongly agree, agree, neutral, disagree and strongly disagree. This questionnaire contained statements, the considering three dimensions as stereotype of women ('think leader think male' attitude), work/family conflict (lack of sufficient family time, missing family responsibilities and stress) and unfavorable corporate practices (lack of recruitment, lack of training and development opportunities and lack of mentoring). Each dimension i.e. stereotype of women, work/family conflict and unfavorable corporate practices were measured by their responses to the questionnaire with five point Likert scales.

In order to examine the impact of personal, societal and organizational barriers on women career progression, following regression model was run.

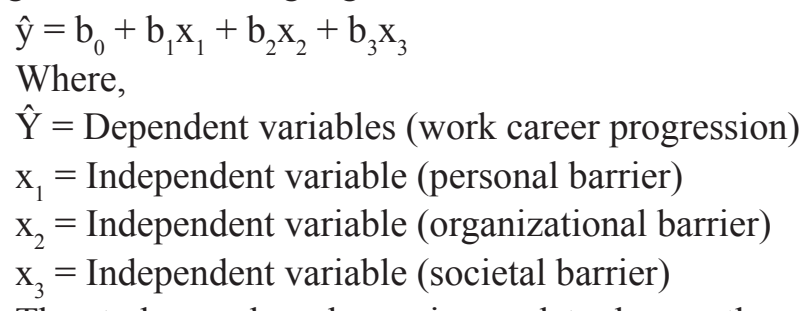

The study was based on primary data; hence, the reliability of the study was highly determined by the quality and reliability of the responses of the respondent. High reliability represents the data are closer to the reality. In order to check the reliability, Cronbach's coefficient alpha test was conducted on SPSS. If the result is more than 0.7 the study is said to be reliable or closer towards the reality. The value of Cronbach alpha resulted to be 0.727 , which indicates the data are reliable and there is internal consistency among data.

\section{RESULTS AND DISCUSSION}

\subsection{Demographic Characteristics of the Respondents}

The demographic characteristics of the respondents sections included position of the employee, types of banks, age, salary, education, caste, duration of work and marital status. The demographics characteristics of the respondents in terms of the position of the employee, types of banks, age, salary, education, caste, duration of work and marital status are presented in Appendix A. There were altogether seven items to analyze the profile status of the respondents. Altogether number of the respondents was 99 from different types of financial institutions. However, their individual details status has been explained in the following ways:

Most of the respondents' categorized under assistant level positions. The majority of the respondents were from commercial banks. Majority of the respondents were Janjati community. Majority of the respondents have completed graduation degree. The age group of the respondents was mostly between 
21 to 25 years of age. Regarding the marital status, 43.4 percent of the respondents were found married and the rest 56.6 were single. The majority of the respondents experience categorized under four to eight years and less than one year of working experience. The salary range of majority respondents was between Rs. 15,000 to Rs. 25,000 .

Table 2

Descriptive Statistics of Relationship of Personal, Societal and Organizational Barriers Towards Women Career Progression

\begin{tabular}{lrrrr}
\hline Variables & N & Minimum & Maximum & Mean \\
\hline Personal barrier & 99 & 2.20 & 5.00 & 3.8889 \\
Organizational barrier & 99 & 2.40 & 4.80 & 3.5939 \\
Societal barrier & 99 & 1.00 & 5.00 & 3.0929 \\
Work career progression & 99 & 1.80 & 4.80 & 3.4263 \\
\hline
\end{tabular}

The variables, personal barrier, societal barrier and organizational barrier, show in Table 2, are the independent variables whereas women career progression is the dependent variable. The five points Likert Scale determine strongly agree, agree, neutral, disagree and strongly disagree as 1,2,3,4 and 5 respectively. Thus, the mean of the personal barrier was 3.889 which resulted that it has positive relationship with work career progression as referring to Table 3, similarly the minimum and maximum was found 2.20 and 5 respectively. Also, as referring to Table 3 organizational barrier has found to have positive relationship with work career progression having mean of 3.5939 and 2.40 minimum range and 4.80 maximum ranges. However, referring to Table 3, societal barrier has been found to have more positive relationship with work career progression having mean of 3.0929 which was nearer to 3 and it was also found to have been fallen in range of minimum 1 and maximum 5 .

Table 3

Effects of Personal, Societal and Organizational Barrier on Women Career Development

\begin{tabular}{lrrrrrr}
\hline & 1 & 2 & 3 & 4 & Skewness & Kurtosis \\
\hline WCP & 1 & & & & -0.508 & -0.079 \\
Personal barrier & $0.353^{* *}$ & 1 & & & -0.584 & -0.464 \\
Organizational barrier & $0.495^{* *}$ & $0.189^{* *}$ & 1 & & -0.257 & -0.460 \\
Societal barrier & $0.426^{* *}$ & $0.190^{* *}$ & $0.168^{* *}$ & 1 & 0.013 & 1.433 \\
\hline
\end{tabular}

Note. ${ }^{* *}$ Correlation is significant at the 0.01 level (two-tailed)

Table 3 shows that societal barrier, personal barrier and organizational barrier has positive significance relationship with work career progression having mean of 3.0929, 3.889 and 3.5939 respectively. Multiple regressions were performed with women career progression as dependent variables and personal barrier, organizational barrier and societal barrier as independent variables. The regression output was shown in Table 4 . The adjusted R2 of 0.391 indicated that independent variables explained by 39.1 percent of the variance of the dependent variable. The relationship between independent and dependent variable was positive. The increase in barriers will increase in glass ceiling. The F value of 
Table 4

Regression Analysis of Effects of Personal, Societal and Organizational Barrier on Women Career Development:

\begin{tabular}{ll}
\hline Variables & Beta coefficient \\
\hline Personal barrier & $0.217^{* *}$ \\
Organizational barrier & $0.401 * *$ \\
Societal barrier & $0.317^{* *}$ \\
Adjusted R2 & 0.391 \\
F Value & $22.016^{* *}$ \\
\hline
\end{tabular}

Note. Standardized $\beta$ Coefficient $* \mathrm{p}<0.05$

$\hat{\mathrm{y}}=\mathrm{b}_{0}+0.217 \mathrm{x}_{1}+0.401 \mathrm{x}_{2}+0.317 \mathrm{x}_{3}$

22.016 is significant at the level of 0.05 which indicates that the model is appropriate and fits the collected data. The VIF value of personal, organizational and societal barrier are 1.066, 1.057 and 1.057 respectively which validated that there is no multicollinearity issues among independent variables .Thus, the model fit the collected data.

A closer examination of the standardized coefficients of the multiple regressions revealed that all hypotheses were supported at $\mathrm{p}<0.05$. More specifically, $\mathrm{H}_{1}$ posited that personal barrier has a positive impact on women career progression. The table demonstrated that the results were significant $\left(\beta_{1}\right.$ $=0.217$, $\mathrm{t}$-value $=2.667, \mathrm{p}=0.05$ ). Thus, $\mathrm{H}_{1}$ was sustained and personal barrier does have an impact on women career progression. $\mathrm{H}_{2}$ posited that organizational barrier has a positive impact on women career progression. The results were significant $\left(\beta_{2}=0.401\right.$, $\mathrm{t}$-value $\left.=4.947, \mathrm{p}=0.05\right)$. Thus, $\mathrm{H}_{2}$ was sustained and organizational barrier does have an impact on women career progression. $\mathrm{H}_{3}$ posited that societal barrier has a positive impact on women career progression. The results were significant $\left(\beta_{3}=0.317\right.$, $\mathrm{t}$-value $=3.914, \mathrm{p}=0.05)$. Thus, $\mathrm{H}_{3}$ was sustained and societal barrier does have an impact on women career progression. Based on these figures, the highest standardized coefficient appeared for organizational barrier followed by societal barrier and personal barrier, the possibility that they will barrier for career progression, supporting $\mathrm{H}_{1}-\mathrm{H}_{3}$.

\subsection{Discussion}

The highest post of the respondents was fallen under assistant level employee that was 77.8 percent. The higher employee respondents were from commercial banks. The highest ethnic group was Janjati having 41.4 percent where Dalit were only one percent. Graduate level respondents were 45.5 percent and Master's level students were 43.3 percent. Majority of the respondents were fallen between ages of 21 to 35 which was 69.7 percent of the total respondents. Also 43.4 percent of the respondents were found married and rest were found single. There were 20.2 percent of the employee having experience more than 9 years. There was 5.2 percent of the employee getting salary above 45000 whereas majority of the employee have salary range between Rs. 15,000 to Rs. 35,000 which was 63.7 percent.

\section{Personal Barrier}

The employees who have confident with their abilities were found 92.9 percent. The respondents consider themselves as a leader was 64.6 percent however 18.2 percent of the respondents did not consider themselves as a leader. The respondents consider themselves as a competitive was 64.6 percent however 
18.2 percent of the respondents did not consider competitive. Similarly, 77.8 percent of respondents responded ambitious in comparison to men. Also, the respondents did not consider themselves as weak, too hesitant and illogical were 79.8 percent.

Organizational Barrier

The employees who have received enough organizational support in order to manage professional or domestic responsibilities were 74.7 percent. Similarly, the employee who have achieved higher position in the organization was found 77.7 percent. However, 18.1 percent disagreed with it. Majority (62.3 percent) of the respondents disagreed about having lack in commitment to equality of genders. However, 18.2 percent respondents agreed about organization lack in commitment to equality of genders. Similarly, 60.7 percent respondents disagreed on the statement that personal appraisal favor men whereas 16.2 percent found agreeing with it. The majority (66.7 percent) respondents disagreed about having discouraging culture in the organization whereas 13.1 percent agreed with it.

\section{Societal Barrier}

The highest percentage $(60.6 \%)$ of the respondents found inability to move if job requires whereas, 18.2 percent found agreed with it. Similarly, 64.6 percent responded difficulty in maintaining balance between family affairs and job responsibilities. The respondents agreeing on having bad effect on family life when more job responsibilities are added was 34.4 percent. Similarly, 56.5 percent responded that without family's help in housework, they would not accept high post. The respondents percentage that responded agree to the barrier for career progress due to commitment to family was 16.1 percent. However, 63.6 percent responded negative to it.

\section{Women Career Progression}

The respondents that responded disagree about the employee put up for the promotion of men was $61.8 \%$ whereas $24.2 \%$ showed agree with it. Similarly, the respondents responded that there is existence of gender based barriers in their career success was 30.3 percent. Also, 24.3 percent responded that they feel unwelcomed member of the organization. And 14.1 percent responded that they have less opportunity than men for career progress at work. There were 17.2 percent respondents who responded that organization's support/trust in men more than women to reach top.

\section{Analysis between Societal Barriers and Moderate Variables}

There was high rate of difficulty in maintaining balance between family affairs and job responsibilities among employee working at commercial bank which was 31.3 percent. There was high rate of difficulty in maintaining balance between family and job responsibilities among Janjati which was 26.3 percent. The high rate of difficulty to maintain family affairs and job responsibilities was among academic level of master's which was 27.3 percent. The highest rate of inability to accept high post without family's support in housework was exist among employee working at development bank, which was 24.2 percent. The highest rate of inability to accept high post without their family's housework support was found among Janjati which was 22.2 percent. The highest rate of inability of accepting high post without their family's housework support was seen among master's level employee that was 24.3 percent. There has been found to have significance positive relationship of personal barrier, societal barrier and organizational barrier towards work career progression. 


\section{Effect GC on Bank Type}

It is found that there is significant positive relationship of societal barrier average score by bank. It stated that personal barrier was seen much in development bank that was 3.6378 which was relatively nearer to 3. Also societal barrier was found in commercial bank where its average mean was 3.0049 .Development bank was found to have lack in work career progression comparatively high than other financial institutions. Organizational barrier was also found relatively high in development bank than commercial and finance bank.

\section{Effect of GC on Ethnicity}

There has been found that personal barrier, organizational and societal barriers as comparison to the caste have significance positive relationship to women career progression. Hence, null hypothesis was rejected. Personal barrier was relatively highly seen among others ethnicity group like Madhesi which was 3.7429. Organizational barrier was found among ethnicity of Brahmans and Chhettri which was 3.5600 and 3.5268 respectively. Societal barrier was found relatively high among Brahmans which was 2.9067. There has also been found that work career progression existed relatively less among Dalit which was 3.2286 .

\section{Effect of GC on Academic Level}

There has been found that personal barrier, organizational and societal barrier as comparison to the academic level have positively significance relationship to women career progression. Hence, null hypothesis was rejected. Personal barrier were found relatively high among respondents of intermediate level which was 3.7. Also Organizational barrier has been found relatively high among Master level respondent which was average mean of 3.5488. Societal barrier has been relatively seen high among employee of intermediate level which was average mean of 2.64. Similarly, work career progression has been relatively found less among graduate level 3.3644. Personal barrier and organizational barrier has been found both negative skewness and kurtosis which indicated that they are left tailed and less than mode of distribution. However, societal barrier has been found of consisting positive skewed of 0.013 and positive kurtosis of 1.433 which was within the range of normal distribution and located at right side of the normal distribution.

\section{CONCLUSIONS}

The study concluded that among the GC factors most influenced factor was societal barrier. Hence, female employee must have to work to avoid the societal barriers such as; difficulty exist in maintaining family and job responsibilities, lack of family support results for not accepting high post. The organization has to conduct activities that focus on maintaining balance between work and family life. Meanwhile, it was found that master's level employee have societal barriers related to not accept high post without family support and maintain job and family responsibilities thus the special programs to address master's level employees should be conducted. Also among ethnicity, Janjati employee felt difficult to maintain family and job responsibilities as well as inability to accept job without family's support. Thus, effective programs focusing on Janjati to mitigate those challenges can have good result. Whereas commercial banks has seen high of employee facing difficulty in maintaining work and job responsibilities and employee of development banks has been found of the challenges to inability of accepting high post without family support. Hence, commercial banks have to focus on mitigating work 
and family life balance whereas development banks have to focus programs to mitigate lack of support from family where employees are unable to accept high post.

Female workers who identified having difficulties balancing work and family indicated that they had too many work and family responsibilities and sometimes they did not have time to accomplish everything effectively. However, various scholars has explained effect of glass ceiling depends on cultural prejudices but more over there is societal impact that stand as a blocking stone for women career progression.

Since there are very few women who are involved in top level positions and the issue need to address are those employees whom have been graduated but still involved in assistant level positions. Hence, special policies, plans and programs are essential to mitigate challenges of maintaining work and family life by the financial institutions. Future researchers can conduct study upon focusing effect of work and family life barrier of employee working in financial institutions and its effect on women career progression.

\section{Appendix A}

\section{Demographic Characteristics of Respondent's}

\begin{tabular}{ll}
\hline Respondents details & Percent \\
\hline Position & 1.0 \\
\hline Manager & 1.0 \\
Assistant manager & 11.1 \\
Officers & 1.0 \\
Senior assistant & 4.0 \\
Supervisor & 77.8 \\
Assistant & 4.0 \\
Others & \\
\hline Age & 2.0 \\
\hline under 21 & 39.4 \\
$21-25$ & 30.3 \\
25-30 & 24.2 \\
30-35 & 4.0 \\
over 35 & \\
\hline Caste & 30.3 \\
\hline Brahmans & 20.3 \\
Chhetri & 41.4 \\
Janjati & 1.0 \\
Dalit & 7.1 \\
Others & \\
\hline Education & 1.0 \\
\hline High school & 10.1 \\
Intermediate & 45.5 \\
Graduate & \\
\hline
\end{tabular}




\section{Appendix A (Continue)}

\begin{tabular}{ll}
\hline Master's & 43.4 \\
\hline Marital Status & \\
\hline Married & 43.4 \\
Single & 56.6 \\
\hline Service Years & 28.3 \\
\hline less than 1 & 28.3 \\
1-3 & 23.2 \\
$4-8$ & 20.2 \\
9-15 & \\
\hline Salary & 9.1 \\
\hline below Rs.15,000 & 38.4 \\
Rs. 15,000 to Rs. 25,000 & 25.3 \\
Rs.25,000 to Rs.35,000 & 12.1 \\
Rs.35,000 to Rs.45,000 & 15.2 \\
above Rs.45,000 &
\end{tabular}

Source: Field survey 2018

\section{REFERENCES}

Aaltio, I., \& Huang, J. (2007). Women managers' careers in information technology in China: High flyers with emotional costs? Journal of Organizational Change Management, 20(2), 227-244. doi. org/10.1108/09534810710724775

Aidoo, E., \& Achira, D. C. (2016). Factors that influence the glass ceiling: Evidence from formal sector organizations in Ghana. Journal of Economics, Management and Trade, 1-13.

Adhikary, J. R. (2016). Barriers to career progression: A study of the perceptions of Nepali women employees. Journal of Business and Management Research, 1(2), 17-32.

Adler, N. J., \& Izraeli, D. N. (1994).Competitive frontiers: Women managers in a global economy. Cambridge, MA: Blackwell.

Afza, S.R., \& Newaz, M. K. (2008). Factors determining the presence of glass ceiling and influencing women career advancement in Bangladesh. BRAC University Journal, 5(1), 85-92.

Black, J. S., \& Gregerson, H. B. (1999). Globalizing people through international assignments. Reading MA: Addison Wesley.

Blank, R. M. (1996). Report of the committee on the status of women in the economics profession. American Economic Review, 86(2), 502-506.

Bilimoria, D., \& Piderit, S. K. (1994). Board committee membership: Effects of sex-based bias. Academy of Management Journal, 37(6), 1453-1477. Retrieved from http://dx.doi.org/10.2307/256795

Caligiuri, P. M., \& Tung, R. (1999). Comparing the success of male and female expatriates from a US-based company. International Journal of Human Resource Management, 10(5), 163-179. Retrieved from http:// dx.doi.org/10.1080/095851999340143 
Central Bureau of Statistics. (2009). Report of the Nepal labour force survey 2008. Kathmandu: Author.

Davidson, M. (2009). The glass ceiling - Australian and British women in management 2009: Myth or reality? Paper presented at the $44^{\text {th }}$ Australian Psychological Society Annual Conference, September 30 - October 4, 2009. Darwin, Australia.

Eagly, A. H., \& Carli, L. L. (2007).Through the labyrinth: The truth about how women become leader. Boston, MA: Harvard Business School.

Fassinger, R. E. (2008). Workplace diversity and public policy: challenges and opportunities for psychology. American Psychologist, 63(4), 252-268. http://dx.doi.org/10.1037/0003066X.63.4.252

Hansatit, P. (2014). A study on gender inequality in Thailand: Career experience of Thai female managers (Doctoral thesis, Southern Cross Business School, Southern Cross University). Retrieved from https://epubs.scu.edu. $\mathrm{au} /$ cgi/viewcontent.cgi?referer=https:// scholar.google.com/ \&httpsredir=1\&article=1403\&context=theses

Luthans, F. (2011). Organizational behaviour (12 ${ }^{\text {th }} \mathrm{ed}$.). New Delhi: McGraw-Hill.

Maskell-Pretz, M., \& Hopkins, W.E. (1997). Women in engineering: Toward a barrier-free work environment. Journal of Management in Engineering, 1(2), 32-37. http://dx.doi.org/10.1061/(ASCE)0742-597X(1997)13:1(32)

Meyerson, D. E., \& Fletcher, J. K. (2000). A Modest Manifesto for Shattering the Glass Ceiling. ADVANCE Library Collection, Paper 190.

Nepal Rastra Bank. (Mid-Jan 2018). Mid-term review of monetary policy-2074/075. Retrieved from https://nrb.org. np/ofg/monetary_policy/Monetary_Policy_(in_Nepali)--2074-75_Mid_Term_Review_(Full_Text)-new.pdf

Othman, Z., \& Othman, N. (2015). A literatural review on work discrimination among women employees. Asian Social Science, 11(4), 26.

Rana, B. (2007). A study on women's perception of glass ceiling in the private organizations. The Journal of Nepalese Business Studies, 4(1), 83-87.

Tan, J. (2008). Breaking the bamboo curtain and the glass ceiling: The experience of women entrepreneurs in hightech industries in an emerging market. Journal of Business Ethics, 80(3), 547-564. Retrieved from http:// dx.doi.org/10.1007/s10551-007-9454-9

Tharenou, P. (2001). Going up? Do traits and informal social processes predict advancing in management? The Academy of Management Journal, 44(5), 1005-1017. Retrieved from http://dx.doi.org/10.2307/3069444 